\section{AB0730 COMPARISON OF A SINGLE-CENTRE IDIOPATHIC INFLAMMATORY MYOPATHY COHORT FROM ARGENTINA WITH THE EUROMYOSITIS INTERNATIONAL REGISTRY}

A.S. Braillard Poccard, R. Gomez, M. Pino, M. Garcia Carrasco, D. Dubinsky. Hospital de Clinicas "Jose de San Martín", Ciudad Autonoma de Buenos Aires, Argentina

Background: The idiopathic inflammatory myopathies (IIM) are rare systemic autoinmune diseases that affect the muscle and other organs. Ttraditionally, IIM encompasses polymyositis (PM) and dermatomyositis (DM), but progressively inclusion body myositis (IBM), Immune-mediated necrotising myopathy (IMNM), the antisynthetase syndrome (ASS) and connective tissue diseases-ovler myositis (CTD-OM) have been recognised within the IIM spectrum

Objectives: To compare the clinical characteristics and treatment in a IIM cohort from an Argentinian universitary hospital with the international IIM cohort EUROMYOSITIS

Methods: Descriptive, retrospective study. IIM patients defined by expert opinion followed in our centre between October 2007 and October 2017 were included. ASS was defined by the presence of arthritis, raynaud's phenomenon, mechanic hands, elevated CK, muscle weakness, interstitial lung disease and/or presence of antisynthetase antibodies and, as in EUROMYOSITIS, patients with IIM with positive antisynthetase antibodies were reclassified as ASS. CTD-OM was defined as patients with IIM fulfilling classification criteria for other CTD.

Demographic data, accumulated clinical features, time interval between disease onset and diagnosis, IIM subtype, treatment and presence of neoplasm were evaluated.

Ethnicity was defined using the same classification as in EUROMYOSITIS

Results: 58 patients were included: DM 24, PM 4, ASS 10, CTD-OM 20. 89.6\% Hispanic, mean age $48.4 \pm 15.2$ years, median time interval between disease onset and diagnosis 5 months (IQR 2-11 months), been higher in AAS (8.5 months, IQR 1.5-18.2 months). 6,89\% (4/58) patients presented associated neoplasm, 3 with DM and 1 with CTD-OM. Table 1 shows the demographic and clinical features of our IIM cohort and EUROMYOSITIS. Table 2 shows treatments received in our cohort and EUROMYOSITIS.

Abstract AB0730 - Table 1. Demographic and clinical features

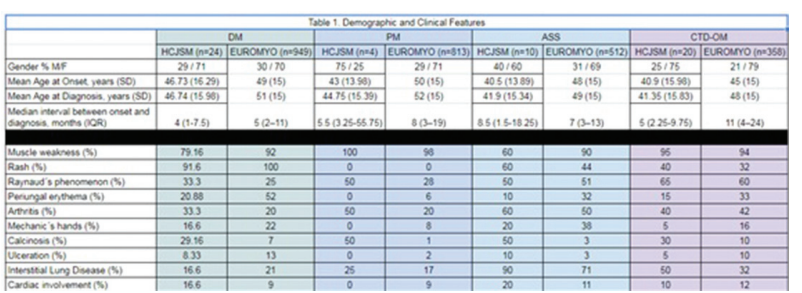

Conclusions: DM was the most frecuent IIM subtype in both cohorts. In our group, CTD-OM was second and ASS was third.

Muscle weakness was found less frecuently in our DM and AAS than reported in EUROMYOSITIS. However, calcinosis was more frecuent. This could be explained by our mostly Hispanic population and/or by frecuent Systemic Sclerosis overlap in our patients. It's important to remark that the ethnic variety defined as Hispanic in EUROMYOSITS has a complex composition in Latin America, due to interbreeding.

No difference was found in therms of most frecuent treatments between both cohorts. However, use of IVIg was more frecuent in our patients.

To our knowledge, this is the first comparative report of an argentinian singlecentre IIM cohort and an international multi-centre cohort

Disclosure of Interest: None declared

DOI: 10.1136/annrheumdis-2018-eular.6539

\section{$\mathrm{AB} 0731$ \\ TREATMENT ALGORITHMS FOR SYSTEMIC SCLEROSIS ACCORDING TO EXPERTS}

A. Fernández-Codina ${ }^{1,2}$, K.M. Walker ${ }^{3}$, J.E. Pope ${ }^{1}$, on behalf of Scleroderma Algorithm Group. ${ }^{1}$ Medicine, Rheumatology Division, University of Western Ontario, London, Canada; ${ }^{2}$ Internal Medicine, Systemic Autoimmune Diseases Unit, Hospital Universitari Vall d'Hebron, Universitat Autònoma de Barcelona, Barcelona, Spain; ${ }^{3}$ Rheumatology Division, The Ottawa Hospital, University of Ottawa, Ottawa, Canada

Background: Treatment for many aspects of systemic sclerosis (SSc) lacks agreement.

Objectives: To generate SSc treatment algorithms endorsed by high percentage of SSc experts.

Methods: Experts from the Scleroderma Clinical Trials Consortium and the Canadian Scleroderma Research group $(n=170)$ were asked whether they agreed with SSc algorithms (from 2012 1 ). A further 2 consensus rounds refined agreement; 62 (36\%), 54 and 48 experts completed surveys.

Results: For scleroderma renal crisis (SRC), $82 \%$ of the experts agreed (1st line ACEi, 2nd and 3rd adding: CCB or ARB). Pulmonary arterial hypertension (PAH) had $81 \%$ agreement. For mild PAH, PDE5i, then endothelin receptor antagonists plus PDE5i, then prostanoids; while for severe PAH prostanoids were first-line. Raynauds' phenomenon (RP) had $78 \%$ of agreement [mild (1st CCB, 2nd adding PDE5i, 3rd ARB or switching to another CCB, 4th prostanoids), severe (1st CCB, 2nd adding PDE5i, 3rd ERA, 4th prostanoids)]. Digital ulcer (DU) treatment had $69 \%$ agreement (1st CCB, 2nd PDE5i). Interstitial lung disease (ILD) had 65\% agreement including induction (Mycophenolate mofetil (MMF) then intravenous cyclophosphamide then rituximab) and maintenance (1st line MMF). Skin involvement had $71 \%$ agreement. For a modified Rodnan skin score (mRSS) of $241 \mathrm{st}$ MTX, 2nd MMF; and for mRSS 32 1st MMF, 2nd MTX, 3rd intravenous cyclophosphamide (CYP), 4th hematopoietic stem cell transplantation. For inflammatory arthritis $79 \%$ agreed with 1st MTX, 2nd low dose glucocorticoids, 3rd hydroxychloroquine, 4th rituximab or tocilizumab. Cardiac and gastrointestinal algorithms had $\geq 75 \%$ agreement. The evolution of the agreement rates is shown in table 1 :

\begin{tabular}{lcc} 
Abstract AB0731 - Table 1 & \\
\hline Algorithms for SSc treatment & Agreement 2012 & \\
\hline Scleroderma renal crisis & Agreement 2017 (\%) \\
Pulmonary arterial hypertension & 69 & 82 \\
Raynaud's phenomenon & 45 & 81 \\
Digital ulcers & 66 & 78 \\
Interstitial lung disease & 58 & 69 \\
Gastrointestinal involvement & 64 & 65 \\
Skin involvement & $\mathrm{NA}$ & 77 \\
Inflammatory arthritis & $56,40,36^{\dagger}$ & 71 \\
Cardiac involvement & 45 & 79 \\
\end{tabular}

Agreement is the \% who agreed to the algorithm.

SSc: Systemic Sclerosis; NA: Not applicable; †For modified Rodnan skin scores 10,24 and 32 , respectively

Conclusions: Total agreement for SSc algorithms was considerable. These SSc algorithms may guide treatment.

\section{REFERENCE:}

[1] Walker KM, Pope J. Treatment of Systemic Sclerosis Complications: What to Use When First-Line Treatment Fails-A Consensus of Systemic Sclerosis Experts. Semin Arthritis Rheum 2012;42:42-55.

Disclosure of Interest: A. Fernández-Codina Grant/research support from Spanish Federation for Internal Medicine; Ontario Scleroderma Association, K. Walker: None declared, J. Pope Grant/research support from: AbbVie, Actelion, Amgen, BMS, GSK, Lilly, Merck, Novartis, Pfizer, Roche, Sandoz, Sanofi, UCB

Abstract AB0730 - Table 2. Treatment

\begin{tabular}{|c|c|c|c|c|c|c|c|c|}
\hline & \multicolumn{2}{|c|}{ DM } & \multicolumn{2}{|c|}{ PM } & \multicolumn{2}{|c|}{ ASS } & \multicolumn{2}{|c|}{ CTD-OM } \\
\hline & $\begin{array}{c}\text { HCJSM } \\
(n=24)\end{array}$ & $\begin{array}{c}\text { EUROMYO } \\
(\mathrm{n}=949)\end{array}$ & $\begin{array}{c}\text { HCJSM } \\
(n=4)\end{array}$ & $\begin{array}{c}\text { EUROMYO } \\
(\mathrm{n}=813)\end{array}$ & $\begin{array}{c}\text { HCJSM } \\
(n=10)\end{array}$ & $\begin{array}{c}\text { EUROMYO } \\
(\mathrm{n}=512)\end{array}$ & $\begin{array}{c}\text { HCJSM } \\
(n=20)\end{array}$ & $\begin{array}{c}\text { EUROMYO } \\
\quad(n=358)\end{array}$ \\
\hline Steroids & 95 & 98 & 50 & 100 & 90 & 98 & 85 & 96 \\
\hline Hydroxichloroquine & 50 & 37 & 25 & 11 & 40 & 16 & 40 & 29 \\
\hline Methotrexate & 37.5 & 69 & 50 & 76 & 20 & 60 & 25 & 72 \\
\hline Leflunomide & 0 & 0 & 0 & 3 & 20 & 3 & 5 & 4 \\
\hline Azathioprine & 33.3 & 44 & 25 & 52 & 60 & 60 & 35 & 51 \\
\hline Mycophenolate & 0 & 20 & 25 & 20 & 30 & 31 & 10 & 29 \\
\hline Cyclophosphamide & 8.33 & 15 & 0 & 14 & 20 & 39 & 10 & 18 \\
\hline IVlg & 29.16 & 11 & 0 & 13 & 20 & 7 & 5 & 7 \\
\hline
\end{tabular}


Consultant for: AbbVie, Actelion, Amgen, BMS, GSK, Lilly, Merck, Novartis, Pfizer, Roche, Sandoz, Sanofi, UCB

DOI: 10.1136/annrheumdis-2018-eular.2862

\section{AB0732 EFFICACY AND SAFETY OF RITUXIMAB IN SYSTEMIC SCLEROSIS: FRENCH RETROSPECTIVE STUDY AND LITERATURE REVIEW}

M. Thiébaut ${ }^{1}$, D. Launay ${ }^{2}$, S. Rivière ${ }^{1}$, T. Mahévas $^{1}$, S. Bellakhal ${ }^{3}$, E. Hachulla ${ }^{2}$, O. Fain ${ }^{1}$, A. Mekinian ${ }^{1} .^{1}$ Médecine Interne, Hôpital Saint-Antoine AP-HP, Paris; ${ }^{2}$ Médecine Interne, Hôpital Claude Huriez CHU Lille, Lille, France; ${ }^{3}$ Médecine Interne, Hôpital des Forces de Sécurité Intérieure, La Marsa, Tunisia

Background: Interstitial lung disease occurs in $42 \%$ of diffuse SSc patients and have a major impact on the overall survival. ${ }^{1}$ Cyclophosphamide and mycophenolate mofetil can allow the lung disease stabilisation., ${ }^{2,3}$ Recently several casereports and little series reported the efficacy of rituximab in SSc, showing a possible improvement of pulmonary involvements. ${ }^{4,5,6}$ Large studies are lacking to determine the factors associated with rituximab response, the maintenance regimen and the long term efficacy of rituximab in SSc.

Objectives: To describe safety and efficacy of rituximab in patients with systemic sclerosis.

Methods: We included 13 patients with systemic sclerosis treated with rituximab and pooled with 40 additional patients from the literature. SSc rituximab untreated patients were matched to rituximab treated ones.

Results: Thirteen patients who received rituximab and 26 rituximab-untreated patients were included. In comparison to 26 patients who did not received rituximab, FVC changes were not significantly different, whereas DLCO improved in 13 patients who received rituximab $(0[-4 ; 4]$ vs loss of -7 [ $-19 ; 0]$; $p=0.05)$. Considering 7 rituximab treated and 14 untreated diffuse SSc, FVC was improved during the $24^{12 ;} 46$ months of follow up in dSSc who received rituximab (gain of 12 $[7.5: 14] \%$ vs loss of $1.5[-16.8 ; 2.5],(\mathrm{p}=0.003)$. Pooled analysis of 53 patients $(40$ literature patients and 13 from personal series) showed significant improvement of median mRSS from $18^{8 ; 32}$ at baseline to $9^{4 ; 18}$ at M6 $(p=0.007), 13^{8 ; 18}$ at M12 $(p=0.008)$ and $10^{4 ; 16}$ at the last follow-up $(p=0.0002)$. FVC increased from $71 \%{ }^{66}$; 80 at baseline to $84 \%{ }^{75 ;} ; 0$ at M12 ( $\left.p=0.001\right)$. DLCO increased from $58 \%{ }^{39 ; 65}$ at $\mathrm{M} 0 \%$ to $63 \%{ }^{53 ; 78}$ at $\mathrm{M} 12(\mathrm{p}=0.04)$.

Conclusions: Our personal data and pooled literature analysis suggest the efficacy of rituximab in the subset of diffuse SSc in particular in skin and interstitial disease involvements. The safety of rituximab seems to be reasonable and similar to previous data in other autoimmune diseases.

\section{REFERENCES}

[1] Nihtyanova SI, Schreiber BE, Ong VH, et al. Prediction of pulmonary complications and long-term survival in systemic sclerosis. Arthritis Rheumatol Hoboken NJ 2014;66:1625-35.

[2] Tashkin DP, Elashoff R, Clements PJ, et al. Cyclophosphamide in scleroderma lung disease. N Engl J Med 2006;355:1173-1174.

[3] Tashkin DP, Roth MD, Clements PJ, et al. Mycophenolate mofetil versus oral cyclophosphamide in scleroderma-related interstitial lung disease (SLS II): a randomised controlled, double-blind, parallel group trial. Lancet Respir Med 2016:4:708-19.

[4] Lafyatis R, Kissin E, York M, et al. B cell depletion with rituximab in patients with diffuse cutaneous systemic sclerosis. Arthritis Rheum 2009;60:578-83.

[] 5)

Bosello S, De Santis M, Lama G et al. B cell depletion in diffuse progressive systemic sclerosis: safety, skin score modification and IL-6 modulation in an up to thirty-six months follow-up open-label trial. Arthritis Res Ther 2010;12:1

[6] Daoussis D, Liossis S-NC, Tsamandas AC, et al. Experience with rituximab in scleroderma: results from a 1-year, proof-of-principle study. Rheumatology 2010;49:271-80.

Disclosure of Interest: None declared

DOI: 10.1136/annrheumdis-2018-eular.4101

\section{$\mathrm{AB} 0733$}

ASSOCIATION OF HAEMATOLOGICAL PARAMETERS WITH DISEASE MANIFESTATIONS, ACTIVITY, AND SEVERITY IN PATIENTS WITH SYSTEMIC SCLEROSIS

M.E. Yayla ${ }^{1}$, U. İlgen ${ }^{2}$, I.E. Okatann ${ }^{1}$, E. Uslu Yurteri ${ }^{1}$, M. Torğutalp ${ }^{1}$, A.B. Keleşoğlu Dinçer ${ }^{1}$, E.G. Aydemir Gülöksüz ${ }^{1}$, S. Sezer ${ }^{1}$, T.M. Turgay ${ }^{1}$, G. Kınıkı ${ }^{1}$, A. Ates ${ }^{1}$.

${ }^{1}$ Department of Rheumatology, Ankara University Faculty of Medicine, Ankara; ${ }^{2}$ Department of Rheumatology, Trakya University Faculty of Medicine, Edirne, Turkey

Background: Neutrophil-to-lymphocyte ratio (NLR), monocyte-to-lymphocyte ratio (MLR), eosinophil-to-lymphocyte ratio (ELR), basophil-to-lymphocyte ratio $(B L R)$, and mean platelet volume (MPV) may potentially reflect inflammatory status in systemic autoimmune diseases.

Objectives: The aim of this study is to investigate the association of NLR, MLR, ELR, BLR and MPV with disease manifestations, activity and severity in patients with systemic sclerosis (SSc).

Methods: 59 patients with SSc and 50 healthy controls were included in the study. All patients were diagnosed according to the 2013 ACR/EULAR systemic sclerosis classification criteria. Adult patients with SSc and healthy controls were compared in terms of NLR, MLR, ELR, BLR and MPV.

Results: SSc and control groups had similar ages and genders. Lymphocyte number was lower in SSc group compared to controls $(p<0.001)$. SSc group also have higher NLR and MLR (table 1). There were no significant differences in ELR and BLR ratios between SSc patients and controls. Patients with active disease (2.9 [IQR 2.13], $\mathrm{p}=0.042$ ), pulmonary hypertension (PHT), digital ulcers, and tendon friction rubs (TFR) had higher NLRs (table 2). MLR was also higher in dcSSc patients $(0.28$ [IQR 0.73$]$ ) compared to IcSSc $(0.2$ [IQR 0.48] ( $\mathrm{p}=0.045)$, and there were also significant associations with disease manifestations like digital ulcers, tendon friction rubs (table 2 ). MLR was positively correlated with $\mathrm{mRSS}$ (rho $=0.35$ $\mathrm{p}=0.009$ ), Valentini ( $\mathrm{rho}=0.453 \mathrm{p}=0.001$ ) and Medsger ( $\mathrm{rho}=0.283 \mathrm{p}=0.036$ ) scores. According to capillaroscopy images, patients with late stage findings had higher MLRs compared to patients with normal findings ( 0.27 [IQR 0.3 ] vs 0.15 [IQR 0.04], $p<0.001)$. Patients with digital ulcers $(p=0.02)$ and arthritis $(p=0.013$ had higher ELRs and patients with tendon friction rubs has higher ELRs $(p=0.014)$ and BLRs (0.036) compared to those without. There was no significant relation between MPV and disease manifestations (table 2). There were no relationships between dysmotility and haematological parameters.

Abstract AB0733 - Table 1. Comparison of laboratory features of disease and control groups

\begin{tabular}{lccc}
\hline & SSc $\mathbf{n = 5 9}$ & Control $\mathbf{n = 5 0}$ & p value \\
\hline Neutrophil $^{\star}$ & $4.13(11.88)$ & $3.57(5.19)$ & 0.150 \\
Lymphocyte $^{\star}$ & $1.67(3.04)$ & $2.08(2.75)$ & $<0.001$ \\
Monocyte $^{\star}$ & $0.34(1.21)$ & $0.35(0.73)$ & 0.959 \\
CRP, mg/L & $2.3(29.9)$ & $1.2(8.1)$ & $\mathbf{0 . 0 3 1}$ \\
ESR, mm/hour & $19(58)$ & $13(30)$ & 0.092 \\
MPV, fl & $9(4.8)$ & $8.7(5.3)$ & 0.557 \\
NLR & $2.47(7.82)$ & $1.73(2.29)$ & $<\mathbf{0 . 0 0 1}$ \\
MLR & $0.20(0.79)$ & $0.16(0.34)$ & $<\mathbf{0 . 0 0 1}$ \\
\hline
\end{tabular}

${ }^{*} \times 10^{9} / \mathrm{L}(\mathrm{IQR})$

Abstract AB0733 - Table 2. Association of disease manifestations with NLR, MLR and MPV

\begin{tabular}{lcccc}
\hline & $\mathbf{n}=59^{*}$ & MPV & NLR & MLR \\
\hline ILD & $+(n=17)$ & $8.9(2.8)$ & $2.71(7.82)$ & $0.21(0.77)$ \\
& $-(n=42)$ & $9(4.8)$ & $2.43(3.92)$ & $0.2(0.32)$ \\
PHT & $P$ & 0.412 & 0.431 & 0.738 \\
& $+(n=3)$ & $9.2(1.3)$ & $3.2(1.78)$ & $0.26(0.11)$ \\
Digital UIcer & $-(n=56)$ & $9(4.8)$ & $2.43(7.82)$ & $0.2(0.82)$ \\
& $P$ & 0.856 & 0.044 & 0.276 \\
& $+(n=12)$ & $9.1(3.4)$ & $2.75(3.05)$ & $0.27(0.74)$ \\
TFR & $-(n=47)$ & $8.9(4.8)$ & $2.43(4.31)$ & $0.19(0.48)$ \\
& $P$ & 0.971 & 0.049 & 0.009 \\
& $+(n=5)$ & $9.1(1.6)$ & $3.62(1.26)$ & $0.28(0.27)$ \\
& $-(n=54) p$ & $9(4.8)$ & $2.41(4.31)$ & $0.2(0.48)$ \\
& & 0.911 & 0.003 & $\mathbf{0 . 0 3 0}$ \\
\hline
\end{tabular}

MPV, NLR and MLR are given as medians (interquartile ranges).+and - denote presence and absence, respectively.

Conclusions: According to our study, as NLR and MLR are simple, practical, cost-effective markers, they can used for evaluation of disease manifestations, activity and severity in SSc.

Disclosure of Interest: None declared

DOI: 10.1136/annrheumdis-2018-eular.2667 